\title{
Thrombocythemia 1 With THPO Variant (c.13+1G>A) Diagnosed Using Targeted Exome Sequencing: First Case in Korea
}

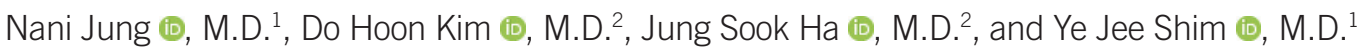 \\ ${ }^{1}$ Department of Pediatrics, Keimyung University School of Medicine, Keimyung University Dongsan Medical Center, Daegu, Korea; ${ }^{2}$ Department of Laboratory
} Medicine, Keimyung University School of Medicine, Keimyung University Dongsan Medical Center, Daegu, Korea

\section{Dear Editor,}

Hereditary thrombocythemia is a very rare autosomal dominant disorder associated with polyclonal hematopoiesis of the megakaryocytic lineage [1, 2]. Thrombocythemia 1 (THCYT1), caused by THPO variant, has been reported in Dutch [3, 4], Japanese [5, 6], Polish [7], Italian [1], Filipino [2], and German [8] families. Here, we report the first case of a Korean boy diagnosed as having THCYT1 using next-generation sequencing (Table 1). This study was approved by the Institutional Review Board of Keimyung University Dongsan Hospital, Daegu, Korea (approval number: 2019-01-015-002). Informed consent was obtained from all individuals in this study.

In September 2017, a 25-day-old male infant was transferred to Keimyung University Dong San Hospital, following an incidental finding of an abnormal white blood cell (WBC) count. He had congenital defects of his left hand (Fig. $1 \mathrm{~A}$ and $1 \mathrm{~B}$ ). One of his two sisters had a history of persistent thrombocythemia of unknown etiology from the age of five months, which was diagnosed at another hospital. His parents and another sister had no past medical history.

Laboratory examination at admission showed a WBC count of $34.6 \times 10^{9} / \mathrm{L}$. His hemoglobin level was $134 \mathrm{~g} / \mathrm{L}$, and the platelet count was $197 \times 10^{9} / \mathrm{L}$. The WBC count, determined by manual differential cell count, gradually increased to $57.61 \times 10^{9} / \mathrm{L}$ with $3 \%$ blasts, $45 \%$ segmented cells, 32\% lymphocytes, 10\% monocytes, $5 \%$ eosinophils, and $1 \%$ basophils at 39 days of age. Bone marrow analysis at 42 days old showed an increase in the myeloid series with some myeloblasts (5.1\%). Megakaryocytes were adequate in number and morphologically normal. We initially suspected juvenile myelomonocytic leukemia; however, clinical and genetic evaluations were inadequate to confirm this diagnosis.

At four months of age, the leukocytosis resolved spontaneously; however, the platelet count increased to $>1,000 \times 10^{9} / \mathrm{L}$ and was sustained at this level (Fig. 1C). There was no evidence of infection, tissue damage, allergic disease, or autoimmune inflammation associated with secondary thrombocythemia. A second bone marrow analysis revealed slightly increased cellularity with an adequate myeloid:erythroid ratio (2.38:1) and no abnormal finding except for increased megakaryocytes (Fig. 1D). Genetic evaluation for essential thrombocythemia was performed for JAK2, JAK2 V617F, MPL, and CALR, and no pathogenic variant was observed. Treatment with low-dose acetyl salicylic acid (3 mg/kg) was initiated at four months of age.

Targeted exome sequencing was performed to determine the genetic cause of the thrombocythemia in the absence of JAK2/ MPLCALR mutation. Library preparation was performed using
Received: June 6, 2019

Revision received: November 15, 2019

Accepted: January 28, 2020

Corresponding author: Ye Jee Shim, M.D., Ph.D. Department of Pediatrics, Keimyung University School of Medicine, 1095 Dalgubeol-daero, Dalseo-gu, Daegu 42601, Korea Tel: +82-53-258-7824, Fax: +82-53-258-4875

E-mail: yejeeshim@dsmc.or.kr

\section{(c) (1) (8)}

\section{(c) Korean Society for Laboratory Medicine}

This is an Open Access article distributed under the terms of the Creative Commons Attribution Non-Commercial License (https://creativecommons.org/licenses/by-nc/4.0) which permits unrestricted non-commercial use, distribution, and reproduction in any medium, provided the original work is properly cited. 
Table 1. Clinical manifestations of reported thrombocythemia 1 families with THPO variant

\begin{tabular}{|c|c|c|c|c|c|}
\hline Published cases & THPO variant & Classification* & Complete blood count & $\begin{array}{l}\text { THPO serum } \\
\text { concentration }\end{array}$ & Clinical manifestations \\
\hline Present case & $c .13+1 G>A$ & Likely pathogenic & $\begin{array}{l}\text { Leukocytosis in infancy } \\
\text { thrombocythemia }\end{array}$ & Increased & $\begin{array}{l}\text { Congenital limb defects: absent distal phalanges of the left } \\
\text { hand }\end{array}$ \\
\hline $\begin{array}{l}\text { Schlemper, et al., } \\
1994 \text { [3] and } \\
\text { Wiestner, et al., } \\
1998 \text { [4] }\end{array}$ & IVS3, G >C, +1 & Likely pathogenic & thrombocythemia & Increased & $\begin{array}{l}\text { Thrombotic complications: tip paresthesia, erythromelalgia, } \\
\text { acrocyanosis, gangrene, transient ischemic attack, carotid } \\
\text { artery stenosis, leg claudication, angina pectoris, stillbirth }\end{array}$ \\
\hline Kondo, et al., 1998 [5] & del3252G & Likely pathogenic & thrombocythemia & Increased & - \\
\hline $\begin{array}{l}\text { Ghilardi, et al., } \\
1999 \text { [6] }\end{array}$ & $516 \mathrm{G}>\mathrm{T}$ & Likely pathogenic & thrombocythemia & Increased & $\begin{array}{l}\text { Hematologic malignancy: cutaneous malignant lymphoma at } \\
4 \text { years of age }\end{array}$ \\
\hline Liu, et al., 2008 [7] & IVS3, G >C, +1 & Likely pathogenic & thrombocythemia & Increased & $\begin{array}{l}\text { Thrombotic complications: Raynaud's phenomenon, transient } \\
\text { ischemic attack, miscarriage, superficial vein thrombosis, } \\
\text { Buerger's disease }\end{array}$ \\
\hline $\begin{array}{l}\text { Graziano, et al., } \\
2009[1]\end{array}$ & $516 \mathrm{G}>\mathrm{T}$ & Likely pathogenic & thrombocythemia & Increased & $\begin{array}{l}\text { Congenital limb defects: absence of the right foot (absence of } \\
\text { the calcaneus and astragalus), unilateral congenital } \\
\text { transverse defect of the right upper (absence of forearm } \\
\text { and hand) and right lower (absence of foot) limbs, milder } \\
\text { lower limb defect in one family member, absence of the last } \\
\text { phalange of digit } 2 \text { and the last two phalanges of digits } \\
3-5 \text {, and left foot defect in one family member }\end{array}$ \\
\hline Zhang, et al., 2011 [2] & IVS2, T>C, +2 & Likely pathogenic & thrombocythemia & Increased & - \\
\hline \multirow[t]{2}{*}{$\begin{array}{l}\text { Stockklausner, et al., } \\
2012[8]^{* *}\end{array}$} & $\mathrm{c} .13+1 \mathrm{G}>\mathrm{C}$ & Likely pathogenic & thrombocythemia & Increased & $\begin{array}{l}\text { Congenital limb defects: absent proximal, middle, and distal } \\
\text { phalanges at digits 3-5; a dysplastic proximal phalanx at } \\
\text { digit } 2 \text { with absent middle and distal phalanx and } \\
\text { shortened metacarpal bones at digits } 3 \text { and } 4 \text {; carpal bones } \\
\text { partly fused to metacarpal bones at digits 2-5. }\end{array}$ \\
\hline & c. $13+1 G>C$ & Likely pathogenic & thrombocythemia & Increased & $\begin{array}{l}\text { Hematologic malignancy: early-onset multiple myeloma at } 39 \\
\text { years of age }\end{array}$ \\
\hline
\end{tabular}

*The variants were classified according to the 2015 ACMG/AMP guidelines based on the descriptions in each study.

**These two families were described together in the same report [8].

Abbreviation: THPO, thrombopoietin.

the TruSight One sequencing panel (Illumina, San Diego, CA, USA). Massively parallel sequencing was conducted using the NextSeq platform (Illumina, San Diego, CA, USA). Sanger sequencing was performed using the primers F-5'-TCAGGACCCAGACCTGAAAC-3' and R-5'-CCTACTCTGCCCAGAAGTGC-3'. Sanger sequencing of samples from the patient and his family members confirmed heterozygosity of a splicing pathogenic variant, NM_000460.2: c.13+1G of THPO for the patient, his father, and the sister with a history of thrombocythemia. His father was presumed to have mosaicism due to a low heterozygous peak. His mother and the other sister possessed the wild-type sequence at c.13+1 of THPO (Fig. 1E). Finally, at 11 months of age, the patient was diagnosed as having THCYT1 with THPO variant $(c .13+1 G>A)$. The pedigree suggested that the patient's disease was inherited in an autosomal dominant manner (Fig. 1F). The patient also showed elevated THPO serum concentration
(182 pg/mL, reference value 7-99 pg/mL) in a manual immunoassay (Quest Diagnostics, Valencia, CA, USA). No thrombotic or hemorrhagic events occurred during the 20-month follow-up period.

THPO is an essential cytokine associated with platelet production and plays an important role in the maintenance of early myeloid progenitors [7]. The multiple upstream AUG codons of the 5 -untranslated region (UTR) in THPO interrupt translation and prevent overproduction of this cytokine [7]. Variants at position +1 of the THPO intron 3 splice donor site result in the skipping of exon 3 and loss of the inhibitory 5 -UTR sequence, thereby disrupting the translational regulation and resulting in increased THPO production and thrombocythemia [4, 7, 8]. A possible mechanism for the early leukocytosis in patients with thrombocythemia can be related to the additional role of THPO in regulating hematopoietic stem cell viability [9, 10]. Several studies 

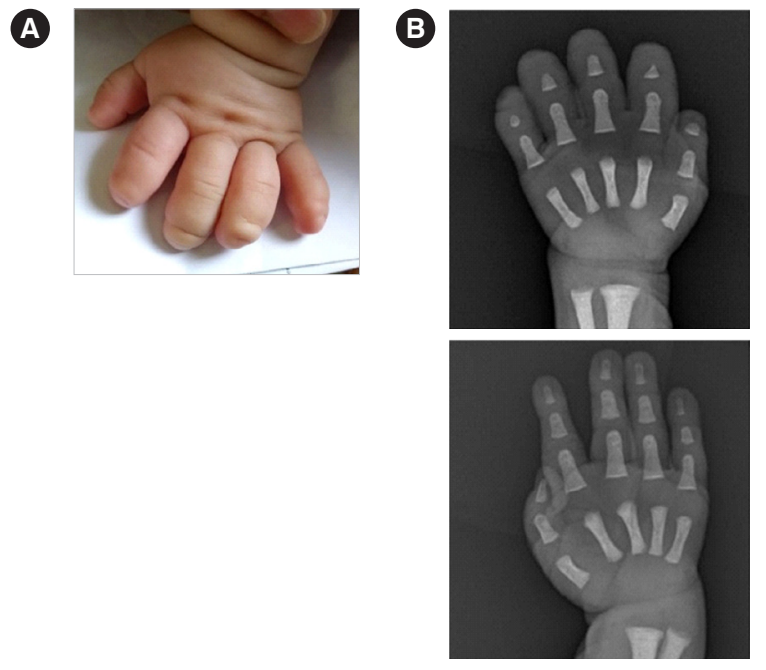

\section{(D)}

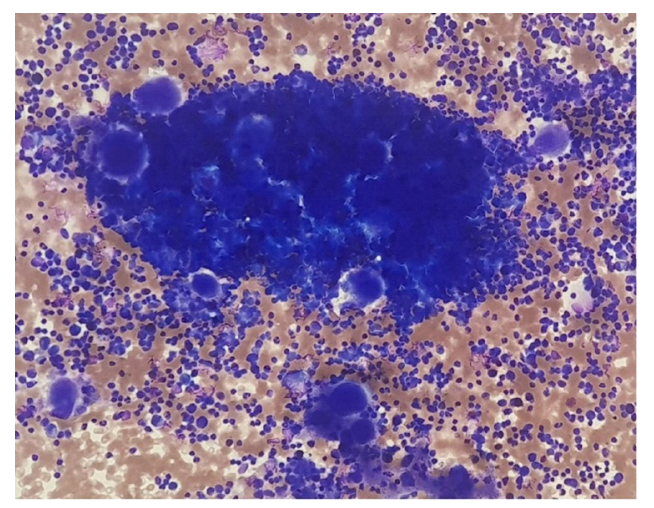

F

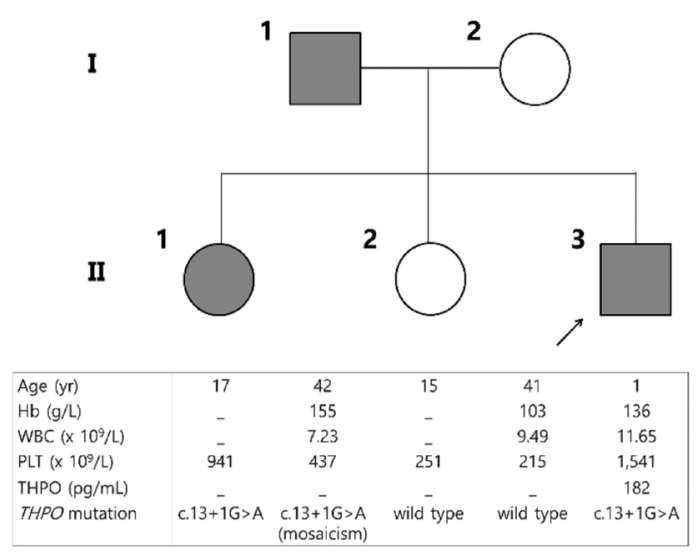

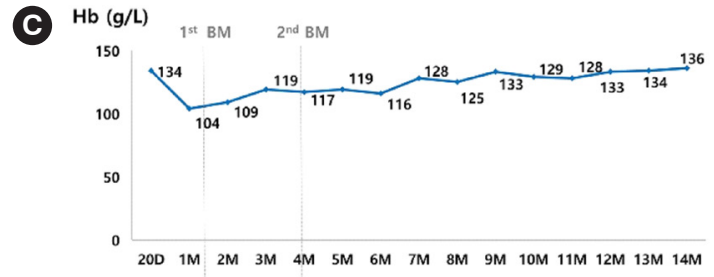

WBC $\left(\times 10^{9} / \mathrm{L}\right)$
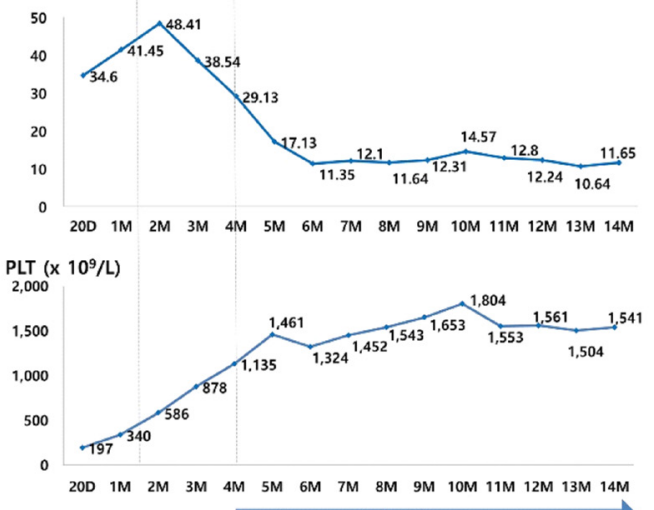

E

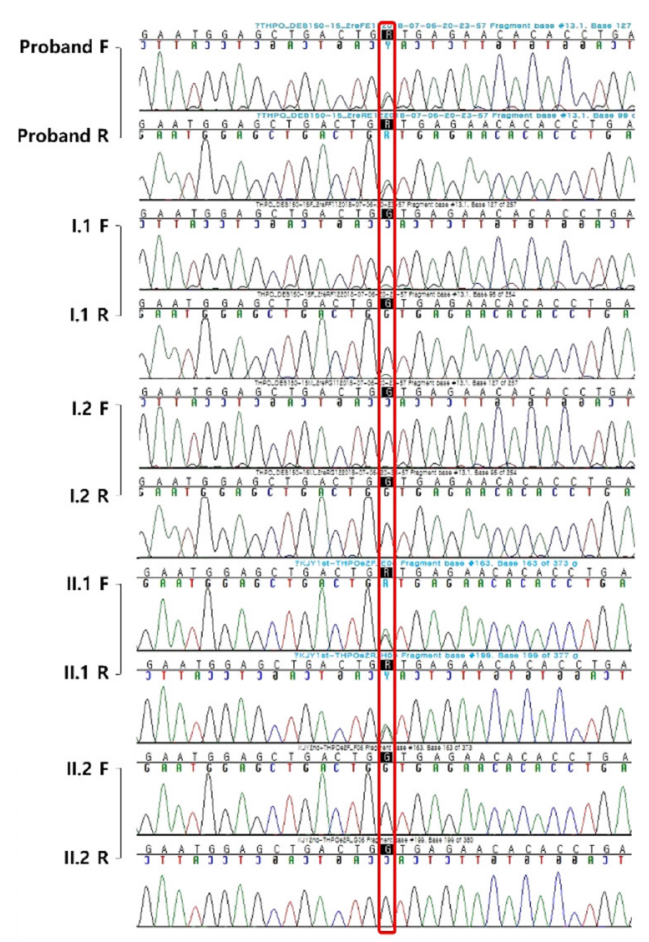

Fig. 1. Clinical features of the thrombocythemia 1 patient. (A) Constricted left hand. (B) Radiographs showing the limb defects of his left hand (missing distal phalanges at digits 2-5) and his normal right hand. (C) Change in the CBC over time. (D) Bone marrow aspirate showing increased megakaryocytes in active form (Wright-Giemsa stain, $\times 100$ ). (E) Sanger sequencing of THPO in the patients and family members. The red square indicates the position of NM_000460.2: c.13+1G. (F) Pedigree of the family with thrombocythemia 1 and laboratory results. The patient is indicated with an arrow. The filled symbols represent individuals with THPO gene variant. Open symbols represent normal individuals. The individuals are indicated above the corresponding lanes. Age, CBC, serum THPO level (reference value, 7 - 99 pg/ $\mathrm{mL}$ ), and THPO variant are shown.

Abbreviations: CBC, complete blood count; THPO, thrombopoietin; F, forward strand; R, reverse strand; Hb, hemoglobin; WBC, white blood cells; PLT, platelets. 
have reported patients with THCYT1 and coexisting congenital distal limb defects, suggesting that THPO is involved in vasculogenesis, as a regulator of hemangioblast $[1,8]$. Hemorrhagic or thrombotic complications have also been reported occasionally $[3,7]$. Although our patient has been successfully treated with low-dose acetyl salicylic acid, an optimal management strategy for hereditary thrombocythemia is yet to be established.

\section{ACKNOWLEDGEMENTS}

None.

\section{AUTHOR CONTRIBUTIONS}

Conceptualization: YJS. Methodology and validation: JSH and DHK. Investigation and data curation: YJS and NJ. Writing - original draft preparation: NJ Writing - review \& editing: YJS. Supervision: YJS, DHK, and JSH. Approval of final manuscript: all authors.

\section{CONFLICTS OF INTEREST}

The authors declare no conflicts of interest.

\section{RESEARCH FUNDING}

None declared.

\section{ORCID}

Nani Jung

https://orcid.org/0000-0003-3941-7498
Do Hoon Kim

https://orcid.org/0000-0002-9854-7850

Jung Sook Ha

Ye Jee Shim

https://orcid.org/0000-0002-5047-3493

\section{REFERENCES}

1. Graziano C, Carone S, Panza E, Marino F, Magini P, Romeo G, et al. Association of hereditary thrombocythemia and distal limb defects with a thrombopoietin gene mutation. Blood 2009;114:1655-7.

2. Zhang B, Ng D, Jones C, Oh ST, Nolan GP, Salehi S, et al. A novel splice donor mutation in the thrombopoietin gene leads to exon 2 skipping in a Filipino family with hereditary thrombocythemia. Blood 2011; 118:6988-90.

3. Schlemper RJ, van der Maas AP, Eikenboom JC. Familial essential thrombocythemia: clinical characteristics of 11 cases in one family. Ann Hematol 1994;68:153-8.

4. Wiestner A, Schlemper RJ, van der Maas AP, Skoda RC. An activating splice donor mutation in the thrombopoietin gene causes hereditary thrombocythaemia. Nat Genet 1998; 18:49-52.

5. Kondo T, Okabe M, Sanada M, Kurosawa M, Suzuki S, Kobayashi M, et al. Familial essential thrombocythemia associated with one-base deletion in the 5'-untranslated region of the thrombopoietin gene. Blood 1998;92:1091-6.

6. Ghilardi N, Wiestner A, Kikuchi M, Ohsaka A, Skoda RC. Hereditary thrombocythaemia in a Japanese family is caused by a novel point mutation in the thrombopoietin gene. Br J Haematol 1999;107:310-6.

7. Liu K, Kralovics R, Rudzki Z, Grabowska B, Buser AS, Olcaydu D, et al. A de novo splice donor mutation in the thrombopoietin gene causes hereditary thrombocythemia in a Polish family. Haematologica 2008;93: 706-14.

8. Stockklausner C, Echner N, Klotter AC, Hegenbart U, Dreger P, Kulozik AE. Hereditary thrombocythemia caused by a thrombopoietin (THPO) gain-of-function mutation associated with multiple myeloma and congenital limb defects. Ann Hematol 2012;91:1129-33.

9. Hitchcock IS and Kaushansky K. Thrombopoietin from beginning to end. Br J Haematol 2014;165:259-68.

10. Kuter DJ. The biology of thrombopoietin and thrombopoietin receptor agonists. Int J Hematol 2013;98:10-23. 